This item was submitted to Loughborough's Research Repository by the author.

Items in Figshare are protected by copyright, with all rights reserved, unless otherwise indicated.

\title{
Manufacture of large uniform droplets using rotating membrane emulsification
}

PLEASE CITE THE PUBLISHED VERSION

http://dx.doi.org/10.1016/j.jcis.2006.01.061

PUBLISHER

(C) Elsevier

VERSION

AM (Accepted Manuscript)

LICENCE

CC BY-NC-ND 4.0

REPOSITORY RECORD

Vladisavljevic, Goran T., and Richard A. Williams. 2012. "Manufacture of Large Uniform Droplets Using Rotating Membrane Emulsification". figshare. https://hdl.handle.net/2134/10156. 
This item was submitted to Loughborough's Institutional Repository (https://dspace.lboro.ac.uk/) by the author and is made available under the following Creative Commons Licence conditions.

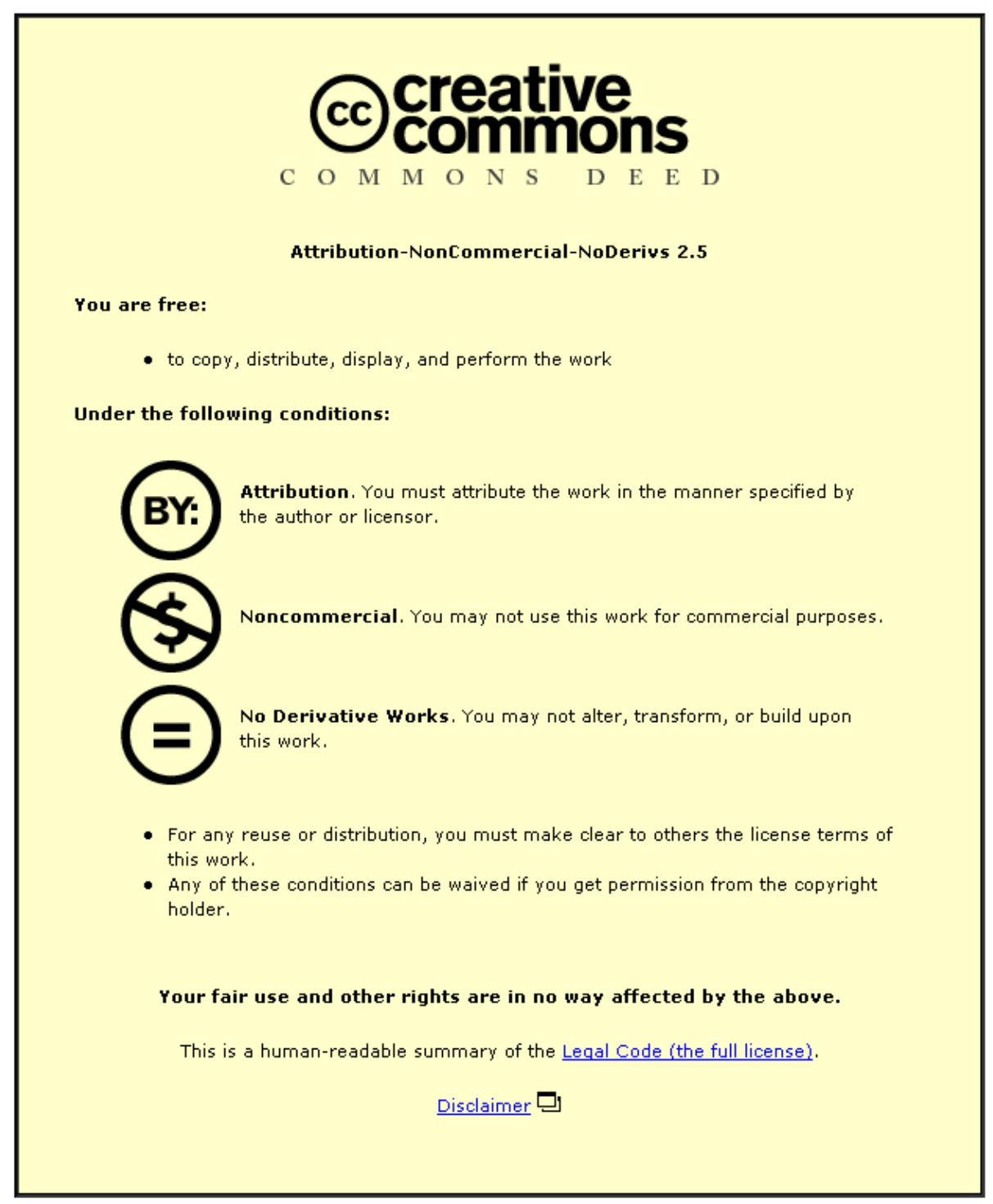

For the full text of this licence, please go to: http://creativecommons.org/licenses/by-nc-nd/2.5/ 


\title{
Manufacture of large uniform droplets using rotating membrane emulsification
}

Goran T. Vladisavljević ${ }^{1 *}$, Richard A. Williams ${ }^{2}$

\author{
${ }^{1}$ Institute of Food Technology and Biochemistry, Faculty of Agriculture, University of \\ Belgrade, P.O. Box 127, YU-11081 Belgrade-Zemun, Serbia \& Montenegro. \\ Tel: (+381) 11615 315/327; Fax: (+381) 11199 711; gtvladis@afrodita.rcub.bg.ac.yu
${ }^{2}$ Institute of Particle Science \& Engineering, School of Process, Environmental \& Materials Engineering, Clarendon Road, University of Leeds, Leeds, LS2 9JT, United Kingdom.

Tel: (+44) (0)113 343 2789/2801; Fax: (+44) (0)113 343 2781; r.a.williams@leeds.ac.uk

*Corresponding author. 


\begin{abstract}
A new rotating membrane emulsification system using a stainless steel membrane with $100 \mu \mathrm{m}$ laser drilled pores was used to produce oil/water emulsions consisting of 2 wt. \% Tween 20 as emulsifier, paraffin wax as dispersed oil phase and 0.01-0.25 wt. \% Carbomer (Carbopol ETD 2050) as stabilizer. The membrane tube, $1 \mathrm{~cm}$ in diameter, was rotated inside a stationary glass cylinder, diameter of $3 \mathrm{~cm}$, at a constant speed in the range 50-1500 rpm. The oil phase was introduced inside the membrane tube and permeated through the porous wall moving radially into the continuous phase in the form of individual droplets. Increasing the membrane rotational speed increased the wall shear stress which resulted in a smaller average droplet diameter being produced. For a constant rotational speed, the average droplet diameter increased as the stabilizer content in the continuous phase was lowered. The optimal conditions for producing uniform emulsion droplets were a Carbomer content of 0.1-0.25 wt. \% and a membrane rotational speed of $350 \mathrm{rpm}$, under which the average droplet diameter was 105-107 $\mu \mathrm{m}$ and very narrow coefficients of variation of 4.8-4.9\%. A model describing the operation is described and it is concluded that the methodology holds potential as a manufacturing protocol for both coarse and fine droplets and capsules.
\end{abstract}

Keywords: membrane emulsification; monodisperse emulsion; rotating membrane emulsification; stainless steel membrane. 


\section{Introduction}

Conventional emulsification devices, such as high-pressure homogenizers and rotorstator systems, generally use inhomogeneous extensional and shear forces and high energy inputs per unit volume to rupture droplets [1]. As a result they generate emulsions with wide droplet size distributions and relatively small mean droplet sizes, up to several micrometers. Further, batch-to-batch consistency is often poor even when similar experimental conditions are deployed. However, some important potential uses of emulsions require the production of larger uniform droplets with a mean size ranging up to several hundreds of micrometers, e.g. in the manufacture of a variety of coherent and structured microparticles and microcarriers through polymerization, gelation, and other secondary reactions/processes in the emulsified droplets.

Development of emulsification methods for producing uniform droplets are rooted in one of two possible manufacturing approaches [2]:

- equipment designs that seek to (a) reduce of process length scales of the turbulent perturbations in the shearing/mixing processes that rupture the liquids, and (b) enhance the degree of uniformity of the shear within the emulsifying chamber;

- the creation of droplets individually (drop-by-drop).

Our work here is concerned with the second route. Several single-drop technologies have been developed for generating uniform droplets, such as injection of liquid through a capillary into another co-flowing immiscible fluid [3, 4], penetration of dispersed phase through microfabricated parallel silicon channels [5] or interconnected channel network 
in microfluidic devices [6,7], and injection of dispersed phase through microporous membranes of different nature (glass, ceramic, metallic, polymeric) [8-14]. Production of various particulate products, such as microspheres and microcapsules, using membrane emulsification routes was recently reviewed by Vladisavljević and Williams [15].

Some specific attributes of existing systems will be considered briefly. 'Direct membrane emulsification' involves the direct (in-situ) formation of droplets by extruding a pure dispersed phase through the membrane into the continuous phase. In 'premix membrane emulsification' fine emulsions are produced by homogenization of coarsely emulsified feeds through the membrane [16]. In order to stimulate droplet detachment from the pore outlets in the direct emulsification, shear stress is generated at the membrane/continuous phase interface by recirculating the continuous phase through the membrane in cross flow [8] or by agitation in a stirring vessel [17]. Zhu et al. [18] have intruduced membrane vibration, through piezoactuation, to help the detachment of droplets and provide an extra control over droplet detachment in crossflow membrane emulsification. The preliminary results showed that a vibrating membrane had a significant effect in reducing the average size of emulsion droplets but only at very low frequencies $(0-100 \mathrm{~Hz})$.

The typical coefficients of variation $\mathrm{CV}^{1}$ of droplet sizes in the direct emulsification using porous glass membranes in crossflow or stirring systems are in the range of $7-20 \%$ and the mean droplet sizes range from less than $1 \mu \mathrm{m}$ to over $60 \mu \mathrm{m}$ [15]. The typical CV

\footnotetext{
${ }^{1}$ For a specific size distribution the coefficient of variation is defined as $C V=\left(\sigma / \mathrm{d}_{\mathrm{av}}\right) \times 100$, where $\sigma$ is the standard deviation of the droplet diameters and $\mathrm{d}_{\mathrm{av}}$ is the number-average droplet diameter.
} 
values in microchannel emulsification are less than $5 \%$ and the mean droplet sizes range from several microns to $100 \mu \mathrm{m}$ [19]. Performing direct emulsification using rectilinear silicon microchannels with oblong cross section, Kobayashi et al. [20] obtained highly uniform droplets with the CV values of less than $2 \%$. They concluded that an elongated cross section of the channels contributed decisively to the formation of monodispersed droplets with and without a continuous phase flow. In order to produce emulsion droplets with a CV below $2 \%$, the slot aspect ratio of the straight-through microchannels should exceed a critical value of 3 [20].

Schadler and Windhab [21, 22] have studied continuous production of W/O emulsions using a rotating nickel membrane with carbon coating deposited on the porous substrate by the PECVD (Plasma-Enhanced Chemical Vapour Deposition) method. The rotating membrane was mounted coaxially inside an outer cylinder and the dispersed phase was forced through the membrane at a fixed flow rate of $12 \mathrm{l} / \mathrm{h}$. The continuous phase was pumped through the gap at different flow rates to adjust the dispersed phase fraction. With increasing the gap width the droplet size decreased, but the disperse phase volume fraction did not influence the droplet size [22].

The rotating membrane concept has been applied earlier in dynamic membrane filters, which can be designed as rotating disk membranes [23] or rotating cylindrical membranes [24]. These filters are most applicable to the clarification of very high concentration suspensions and the separation of biological products [25]. 
A novel rotating membrane emulsification system utilizing a small diameter stainless steel membrane with uniformly spaced laser drilled pores has been investigated in this work. Figure 1a shows a continuous membrane emulsification system with a rotating cylindrical membrane mounted in a stationary vessel. A pure continuous phase is slowly passed upwards into the annulus between the stationary vessel and the membrane tube and a product emulsion is discharged from the top of the vessel. The shear stress is developed by rotating the membrane rather than by flowing the continuous phase, since the crossflow velocity is negligible. The requirement for circulation of the continuous phase along the membrane surface can thus be totally avoided. Compared with cross membrane emulsification methods $[2,14]$ this can be particularly advantageous to the production of coarse emulsions and fragile structured products, in which the droplets and/or particles are subject to breakage during the pump circulation. The dispersed phase passes radially through the porous membrane wall and forms droplets moving into the continuous phase. At high rotational speeds a foot-bearing can be used to avoid the excessive vibration of the membrane tube. The experimental batch rotating membrane system used in this work for emulsification experiments is shown in Figure 1b, and will be described further in Section 2. In this case a smaller gap is used although the conditions employed did not enter the regime of Taylor vortices in the annulus.

\section{Experimental}

\subsection{Materials}

Table 1 lists the composition and properties of $\mathrm{O} / \mathrm{W}$ emulsions produced in this work. 2 \% (wt/wt) Tween 20 (polyoxyethylene sorbitan monolaureate), purchased from Fisher 
Chem., UK, was used as a water soluble emulsifier and 0.01-0.25 \% (wt/wt) Carbomer (Carbopol ETD 2050) obtained from Surfachem Ltd, Leeds, UK was added as a stabilizer. Carbopol ETD 2050 is a trade name of B.F. Goodrich Co. for a crosslinked polyacrylic acid polymer. The dispersed oil phase was paraffin wax (cat. no. 76234) supplied from Fluka.

\subsection{Experimental set-up and procedure}

The experiments have been carried out using a tubular stainless steel membrane with laser-drilled pores. The geometric characteristics of the membrane are given in Figure 2. The membrane pores with a mean size of approximately $100 \mu \mathrm{m}$ are arranged in a cubic array, with an average pitch of $500 \mu \mathrm{m}$. The wall porosity was $3 \%$ and the effective membrane area was $26.7 \mathrm{~cm}^{2}$. The membrane tube was mounted on an IKA Eurostar digital overhead stirrer and situated in a stationary glass cylinder with an inner diameter of $30 \mathrm{~mm}$. The width of annular gap between the rotating membrane and the stationary cylinder was $10 \mathrm{~mm}$. The amount of continuous aqueous phase in the cylinder was 100 $\mathrm{ml}$ and the membrane rotational speed in each experiment was kept constant between 50 and $1500 \mathrm{rpm}$.

The oil was introduced inside the membrane tube by a pipette and permeated through the porous wall under the driving force of a hydrostatic head. The minimum pressure $\mathrm{p}_{\text {cap }}$ at which the dispersed phase can permeate through the membrane is given by:

$\mathrm{p}_{\text {cap }}=\frac{4 \gamma_{\infty} \cos \theta}{\mathrm{d}_{\mathrm{p}}}$ 
where $\gamma_{\infty}$ is the equilibrium interfacial tension between the continuous and dispersed phase and $\theta$ is the contact angle between the dispersed phase and the membrane surface in continuous phase. In this work $\gamma_{\infty}=6.4 \times 10^{-3} \mathrm{~N} / \mathrm{m}$ and the contact angle $\theta$ between the dispersed phase and the membrane surface could be assumed as zero. Therefore, from Eq.

(1) a value for $p_{\text {cap }}$ is estimated as 256 Pa for $d_{p}=1 \times 10^{-4}$ m, which corresponds to a hydrostatic head of only $26 \mathrm{~mm}$ at the oil density of $1000 \mathrm{~kg} / \mathrm{m}^{3}$. The driving pressure in the experiments was slightly higher than the capillary pressure, therefore about $300 \mathrm{~Pa}$.

The aim of this study was to investigate the influence of the membrane rotational speed and the stabilizer content on the properties of the resultant emulsions (the mean droplet diameter and the $\mathrm{CV}$ ) and to find the optimal conditions for producing monodispersed droplets.

\subsection{Determination of the average droplet diameter}

The number-average diameter, $\mathrm{d}_{\mathrm{av}}$ of droplets was observed directly by means of a Nikon model SMZ800 stereoscopic microscope using 4x zoom ratio. The average diameter was determined by manual counting and measuring a large number (typically several hundred) of droplets which were lying in such a position as to present at least a semicircle of silhouette. The uniformity of the droplet sizes was expressed in terms of the coefficient of variation (relative standard deviation).

\subsection{Rheological characterization}

Flow curves were obtained for different carbomer levels in the continuous phase with a stress rate controlled rheometer (Bohlin CVOR 150) over shear rate regions pertinent to 
experimental conditions in the rotating membrane emulsifier (1-40 $\left.\mathrm{s}^{-1}\right)$. All data were obtained at $20^{\circ} \mathrm{C}$ using concentric cylinder measurement geometry. Data are presented in the form of viscosity-shear rate curves.

\section{Results and discussion}

Flow curves of the continuous phase as a function of stabilizer content are shown in Fig. 3. It is seen that the apparent viscosity of the continuous phase strongly depends on the shear rate applied at the membrane surface and the content of stabilizer added. Under laminar flow conditions in the annular space, the shear rate at the membrane surface is directly proportional to the membrane rotational speed, but depends significantly on the width of the annular gap between the rotating membrane and the stationary cylinder. In this work, the membrane rotational speed $n_{1}$ was in the range of $50-1500 \mathrm{rpm}$ and the radius of the membrane tube and stationary cylinder was $R_{1}=0.005 \mathrm{~m}$ and $R_{2}=0.015 \mathrm{~m}$, respectively. Substituting these values into Eq. [A8] in the Appendix gives values for the shear rate at the membrane surface in the range of $1.3-39.3 \mathrm{~s}^{-1}$.

As shown in Figure 4, the average droplet diameter decreases with increase in membrane rotational speed and stabilizer content, as the shear force at the membrane surface, which is a major force driving the droplet detachment, in both cases increases. The effect of rotational speed on the mean droplet size found here is similar to the effect of cross flow velocity in cross flow membrane emulsification [10]. However, it is especially important to note that the droplet/pore size ratio for the given stainless steel membrane is much 
smaller than for the Shirasu porous glass (SPG) and ceramic membranes investigated by Vladisavljević et al. [10]. For the stabilizer content of at least $0.1 \%$ and the membrane rotational speeds exceeding $550 \mathrm{rpm}$, the average droplet diameter was even smaller that the mean pore size $d_{p}$, as can be seen in Figure 4. For a stabilizer content of 0.05-0.1 \%, the optimal rotational speed with regard to droplet size uniformity was found to be 350 rpm. For a small stabilizer content of $0.01 \%$, however, the rotational speed of $1100 \mathrm{rpm}$ was more favorable than $350 \mathrm{rpm}$ (the CV was 11.3 and $10.8 \%$ for 350 and $1100 \mathrm{rpm}$, respectively). It shows that the optimal membrane rotational speed with regard to droplet size uniformity decreases with increase in stabilizer content. The effect of membrane rotational speed on the mean droplet size was much more marked for a lower Carbomer content in the continuous phase. For example, as $n_{1}$ increased from 350 to 1100 rpm, a two-fold reduction in $\mathrm{d}_{\mathrm{av}}$ was observed for a $0.01 \%$ Carbomer and only by $15 \%$ for a $0.1 \%$ Carbomer.

As shown in Figure 5, for a $\mathrm{n}_{1}$ value of $350 \mathrm{rpm}$, the average droplet diameter decreases with increasing the apparent viscosity of continuous phase, i.e. the stabilizer content, but only in the range of 5.3-340 mPa·s. This corresponds to the Carbomer content of 0.01$0.1 \%$. In the range of Carbomer content of 0.1-0.25\%, both $\mathrm{d}_{\mathrm{av}}$ and CV was independent on the stabilizer content. Therefore, in order to obtain uniform droplets at $350 \mathrm{rpm}$, the Carbomer content in the aqueous phase should exceed a critical value of $0.1 \%$. Under these conditions, the average droplet size is some 5-7 \% larger than the pore size and the $\mathrm{CV}$ is slightly less than $5 \%$, which is similar to the CVs reported in emulsification using grooved-type silicon microchannels [5]. 
For a Carbomer content of $0.25 \%$, the CV was only $4.8 \%$ at $350 \mathrm{rpm}$ and almost all droplet diameters lied in a narrow range between 90 and $110 \mu \mathrm{m}$ (the point $\mathrm{C}$ in Fig. 5). For a small Carbomer content of $0.01 \%$ (the point A in Fig. 5), less uniform and much larger droplets were produced, due to smaller shear forces in the continuous phase. The strong effect of Carbomer content on the size of produced droplets is obvious from Figures $6 \mathrm{a}$ and $6 \mathrm{~b}$. The droplets in both figures were produced at the same membrane rotational speed of $350 \mathrm{rpm}$, but the stabilizer content was varied by a factor of 10 .

For a rotational speed of $1500 \mathrm{rpm}$ and a Carbomer content of $0.1 \%$, polydispersed droplets with a CV value of $20 \%$ and an average droplet diameter $17 \%$ smaller than the pore size were produced, as shown in Figure 7. This is believed to be a consequence of partial droplet break up into smaller daughter droplets under the influence of high shear forces. Figure 8 is s typical micrograph of emulsion droplets produced at $1500 \mathrm{rpm}$. Spontaneous detachment of droplets was not possible under stagnant conditions $\left(\mathrm{n}_{1}=0\right)$, due to circular cross section of the pores, which resulted in the formation of large and highly polydispersed droplets under these conditions (Figure 9). The same type of droplet formation behaviour was found earlier by Kobayashi et al. [19] in silicon-based microfabricated channel devices with linear circular pores. 


\section{Conclusions}

Emulsion droplets with an average diameter of 79-259 $\mu \mathrm{m}$ and a CV in the range of 4.8$20 \%$ have been produced using a stainless membrane with $100 \mu \mathrm{m}$ diameter pores rotating with a speed of 50-1500 rpm in a stationary glass cylinder. Both the average droplet diameter and CV decreased with increase in stabilizer content, i.e. continuous phase viscosity. In the range of stabilizer content between 0.1 and $0.25 \mathrm{wt}$. \%, the average droplet diameter and CV was unaffected by the stabilizer content. The optimal membrane rotational speed with regard to droplet size uniformity for a stabilizer content of 0.1-0.25 wt. \% was $350 \mathrm{rpm}$. Under these conditions, the CV was less than $5 \%$ and the average droplet diameter was 5-7 \% larger than the pore size. Spontaneous detachment of droplets was not possible under stagnant conditions resulted in highly polydispersed droplets with a CV of 55 \%. For a rotational speed of $1500 \mathrm{rpm}$, due to partial droplet break up into smaller daughter droplets, an average droplet diameter was $17 \%$ smaller than the pore size and a CV was $20 \%$. Further experiments are needed to investigate the influence of pressure, the type of emulsifier, annular gap, membrane hydrophobicity and ultra high speed rotation on emulsification.

The results demonstrate the potential for the rotating membrane methods as a emulsification method for manufacturing droplets with a consistent and selectable droplet size. Through judicious choice of membrane, continuous phase viscosity (if this can be carried) and rotation rate it is feasible to tune production characteristics. Similar principles are expected to apply to the production of finer emulsions too. 


\section{Appendix}

Consider two cylinders with a radius of $\mathrm{R}_{1}$ and $\mathrm{R}_{2}$ rotating at a constant angular velocity of $\omega_{1}$ and $\omega_{2}$, respectively. The annular gap between the two cylinders is occupied by an incompressible fluid moving in the axial direction due to fluid viscosity. Under steadystate conditions, $\mathrm{v}_{\mathrm{r}}=\mathrm{v}_{\mathrm{z}}=0$ and $\partial / \partial \theta=0$, and the equation of continuity becomes:

$$
\frac{\partial \mathrm{v}_{\mathrm{r}}}{\partial \theta}=0 \quad \therefore \quad \mathrm{v}_{\mathrm{r}}=\mathrm{v}_{\mathrm{r}}(\mathrm{r})
$$

Navijer-Stokes equations are simplified to Eqs. [A2], [A3] and [A4]:

$$
\frac{\mathrm{v}_{\theta}^{2}}{\mathrm{r}}=\frac{\partial \mathrm{p}}{\partial \mathrm{r}}
$$

$v \frac{\mathrm{d}}{\mathrm{dr}}\left(\frac{1}{\mathrm{r}} \frac{\mathrm{d}\left(\mathrm{rv}_{\theta}\right)}{\mathrm{dr}}\right)=0$

$$
\frac{\partial p}{\partial z}=0 \quad \therefore \quad p=p(r)
$$

where $v$ is the kinematic viscosity of fluid and $r$ is the radial distance. The integration of Eq. [A3] using the boundary conditions: $r=R_{1}: v_{\theta}=R_{1} \omega_{1}$ and $r=R_{2}: v_{\theta}=R_{2} \omega_{2}$ yields the velocity profile:

$$
\mathrm{v}_{\theta}=\frac{1}{\left(\mathrm{R}_{2}^{2}-\mathrm{R}_{1}^{2}\right)}\left[\left(\omega_{2} \mathrm{R}_{2}^{2}-\omega_{1} \mathrm{R}_{1}^{2}\right) \mathrm{r}-\frac{\mathrm{R}_{1}^{2} \mathrm{R}_{2}^{2}}{\mathrm{r}}\left(\omega_{2}-\omega_{1}\right)\right]
$$

Hence the fluid velocity is independent on its viscosity. The integration of Eq. [A2] using Eq. [A4] and the boundary condition: $r=R_{1}: p=p_{1}$, gives the pressure profile in the radial direction: 


$$
\begin{aligned}
& \mathrm{p}=\mathrm{p}_{1}+\frac{\rho}{\left(\mathrm{R}_{2}^{2}-\mathrm{R}_{1}^{2}\right)}\left[\left(\omega_{2} \mathrm{R}_{2}^{2}-\omega_{1} \mathrm{R}_{1}^{2}\right)^{2} \frac{\mathrm{r}^{2}-\mathrm{R}_{1}^{2}}{2}-2 \mathrm{R}_{1}^{2} \mathrm{R}_{2}^{2}\left(\omega_{2}-\omega_{1}\right)\left(\omega_{2} \mathrm{R}_{2}^{2}-\omega_{1} \mathrm{R}_{1}^{2}\right) \ln \frac{\mathrm{r}}{\mathrm{R}_{1}}-\right. \\
& \left.-\frac{\mathrm{R}_{1}^{4} \mathrm{R}_{2}^{4}}{2}\left(\omega_{2}-\omega_{1}\right)^{2}\left(\frac{1}{\mathrm{r}^{2}}-\frac{1}{\mathrm{R}_{1}^{2}}\right)\right]
\end{aligned}
$$

The tangential stress at any cylindrical plane can be derived from Eq. [A7]. For example, the tangential stress on the surface of the inner cylinder for $\omega_{2}=0$ :

$$
\tau_{\mathrm{r} \theta, \mathrm{r}=\mathrm{R}_{1}}=\eta\left[\mathrm{r} \frac{\partial}{\partial \mathrm{r}}\left(\frac{\mathrm{v}_{\theta}}{\mathrm{r}}\right)\right]_{\mathrm{r}=\mathrm{R}_{1}}=-\frac{2 \eta \mathrm{R}_{1}^{2} \omega_{1}}{\mathrm{R}_{2}^{2}-\mathrm{R}_{1}^{2}}
$$

The shear rate at the surface of the inner cylinder for $\omega_{2}=0$ :

$$
\mathrm{S}_{\mathrm{r} \theta, \mathrm{r}=\mathrm{R}_{1}}=-\tau_{\mathrm{r} \theta, \mathrm{r}=\mathrm{R} 1} / \eta=\frac{2 \mathrm{R}_{1}^{2} \omega_{1}}{\mathrm{R}_{2}^{2}-\mathrm{R}_{1}^{2}}=\frac{2 \mathrm{R}_{1}^{2}\left(2 \pi \mathrm{n}_{1} / 60\right)}{\mathrm{R}_{2}^{2}-\mathrm{R}_{1}^{2}}=\frac{\pi \mathrm{R}_{1}^{2} \mathrm{n}_{1}}{15\left(\mathrm{R}_{2}^{2}-\mathrm{R}_{1}^{2}\right)}
$$

where $\omega_{1}$ is the angular velocity in $\mathrm{rad} / \mathrm{s}$ and $\mathrm{n}_{1}$ is the rotational speed in rpm. 


\section{Acknowledgement}

This work is supported by a Royal Society (UK, London) short term grant. Thanks are due to David Gladman (Emulsion Systems Limited, Guildford) for valuable advice in experimental development. 


\section{References}

[1] H. Karbstein, H. Schubert, Chem. Eng. Process. 34 (1995) 205.

[2] R.A. Williams, Ingenia, n. 7, February (2001) 1.

[3] C. Cramer, P. Fischer, E.J. Windhab, Chem. Eng. Sci. 59 (2004) 3045.

[4] B. Walther, C. Cramer, A. Tiemeyer, L. Hamberg, P. Fischer, E.J. Windhab, A. Hermansson, J. Colloid Interface Sci. 286 (2005) 378.

[5] S. Sugiura, M. Nakajima, N. Kumazawa, S. Iwamoto, M. Seki, J. Phys. Chem. B 106 (2002) 9405.

[6] T. Nisisako, T. Torii, T. Higuchi, Chem. Eng. J. 101 (2004) 23.

[7] J.D. Tice, H. Song, A.D. Lyon, R.F. Ismagilov, Langmuir 19 (2003) 9127.

[8] T. Nakashima, M. Shimizu, M. Kukizaki, Adv. Drug Deliv. Rev. 45 (2000) 47.

[9] G.T. Vladisavljević, S. Tesch, H. Schubert, Chem. Eng. Process. 41 (2002) 231.

[10] G.T. Vladisavljević, U. Lambrich, M. Nakajima, H. Schubert, Colloid. Surf. A 232 (2004) 199.

[11] G.T. Vladisavljević, H. Schubert, Desalination 144 (2002) 167.

[12] G.T. Vladisavljević, H. Schubert, J. Membr. Sci. 225 (2003) 15.

[13] G.T. Vladisavljević, H. Schubert, J. Disper. Sci. Technol. 24 (2003) 811.

[14] R.A. Williams, S.J. Peng, D.A. Wheeler, N.C. Morley, D. Taylor, M. Whalley, D.W. Houldsworth, Chem. Eng. Res. Des. 76 A (1998) 902.

[15] G.T. Vladisavljević, R.A. Williams, Adv. Colloid Interface Sci. 113 (2005) 1.

[16] G.T. Vladisavljević, M. Shimizu, T. Nakashima, J. Membr. Sci. 244 (2004) 97.

[17] S. Omi, A. Matsuda, K. Imamura, M. Nagai, G.H. Ma, Colloid. Surf. A 153 (1999) 373. 
[18] J. Zhu, D. Barrow, J. Membr. Sci. 261 (2005) 136.

[19] I. Kobayashi, M. Nakajima, K. Chun, Y. Kikuchi, H. Fujita, AIChE J. 48 (2002) 1639.

[20] I. Kobayashi S. Mukataka, M. Nakajima, J. Colloid Interface Sci. 279 (2004) 277.

[21] V. Schadler, E.J. Windhab, Chem. Ing. Tech. 76 (2004)1392.

[22] V. Schadler, E.J. Windhab, Proceed. $10^{\text {th }}$ Aachen Membrane Colloquium, March 2005, p. 585.

[23] J. Engler, M.R. Wiesner, Chem. Eng. Sci. 34 (2000) 557.

[24] C.K. Choi, J.Y. Park, W.C. Park, J.J. Kim, J. Membr. Sci. 157 (1999) 177.

[25] A. Brou, M.Y. Jaffrin, L.H. Ding, J. Courtois, Biotechnol. Bioeng. 82 (2003) 429. 


\section{FIGURE CAPTIONS}

Figure 1. (A) Schematic view of continuous rotating membrane emulsification system.

(B) Batch rotating membrane system used in this work.

Figure 2. Dimensions and pore arrangement of stainless steel membrane used in this work.

Figure 3. Flow curves of the continuous phase at four different stabilizer contents. The range of shear rates applied in the experiments is shown by the arrows.

Figure 4. Effect of membrane rotational speed on the average droplet diameter and the coefficient of variation of droplet diameters for three different stabilizer contents.

Figure 5. Effect of apparent continuous phase viscosity on the average droplet diameter, and the $\mathrm{CV}$ at a fixed rotational speed of $350 \mathrm{rpm}$. The particle size distributions corresponding to the data points $\mathrm{A}, \mathrm{B}$, and $\mathrm{C}$ are shown as insets.

Figure 6. Micrographs of the emulsion droplets produced at a fixed speed of rotation of 350 rpm using two different stabiliser contents: (A) 0.1 wt. \% Carbomer; (B) 0.01 wt. \% Carbomer. 
Figure 7. Particle size distrubution data obtained under different operating conditions.

Figure 8. Micrograph of the emulsion droplets produced at $1500 \mathrm{rpm}$ and a Carbomer content of 0.1 wt. $\%\left(d_{a v}=83 \mu \mathrm{m}, \mathrm{CV}=20 \%\right)$.

Figure 9. Droplet size distributions for emulsions produced under stagnant conditions (0 rpm) and 50 rpm. (A) Micrograph of the emulsion droplets produced at 50 rpm. (B) Micrograph of the droplets produced under stagnant conditions. The Carbomer content was fixed at 0.1 wt. \%. 
Table 1. The composition and properties of O/W emulsions produced in this work.

\begin{tabular}{|c|c|}
\hline Aqueous (continuous) phase & $\begin{array}{l}2 \%(w t / w t) \text { Tween } 20 \text { and } 0.01 \text {, } \\
0.05,0.1 \text { or } 0.25 \%(w t / w t) \\
\text { Carbomer dissolved in distilled water }\end{array}$ \\
\hline Oil (dispersed) phase & Paraffin wax \\
\hline $\begin{array}{l}\text { Apparent viscosity of continuous phase } \\
\text { at } 20{ }^{\circ} \mathrm{C} \text { and } 9.2 \mathrm{~s}^{-1} \text { (350 rpm) }\end{array}$ & 5.3-831 mPa s \\
\hline Equilibrium interfacial tension at $20^{\circ} \mathrm{C}$ & $6.4 \mathrm{mN} / \mathrm{m}$ \\
\hline Average diameter of droplets & $\mathrm{d}_{\mathrm{av}}=79-259 \mu \mathrm{m}$ \\
\hline Coefficient of variation of droplet diameters & $\mathrm{CV}=4.8-20 \%$ \\
\hline
\end{tabular}




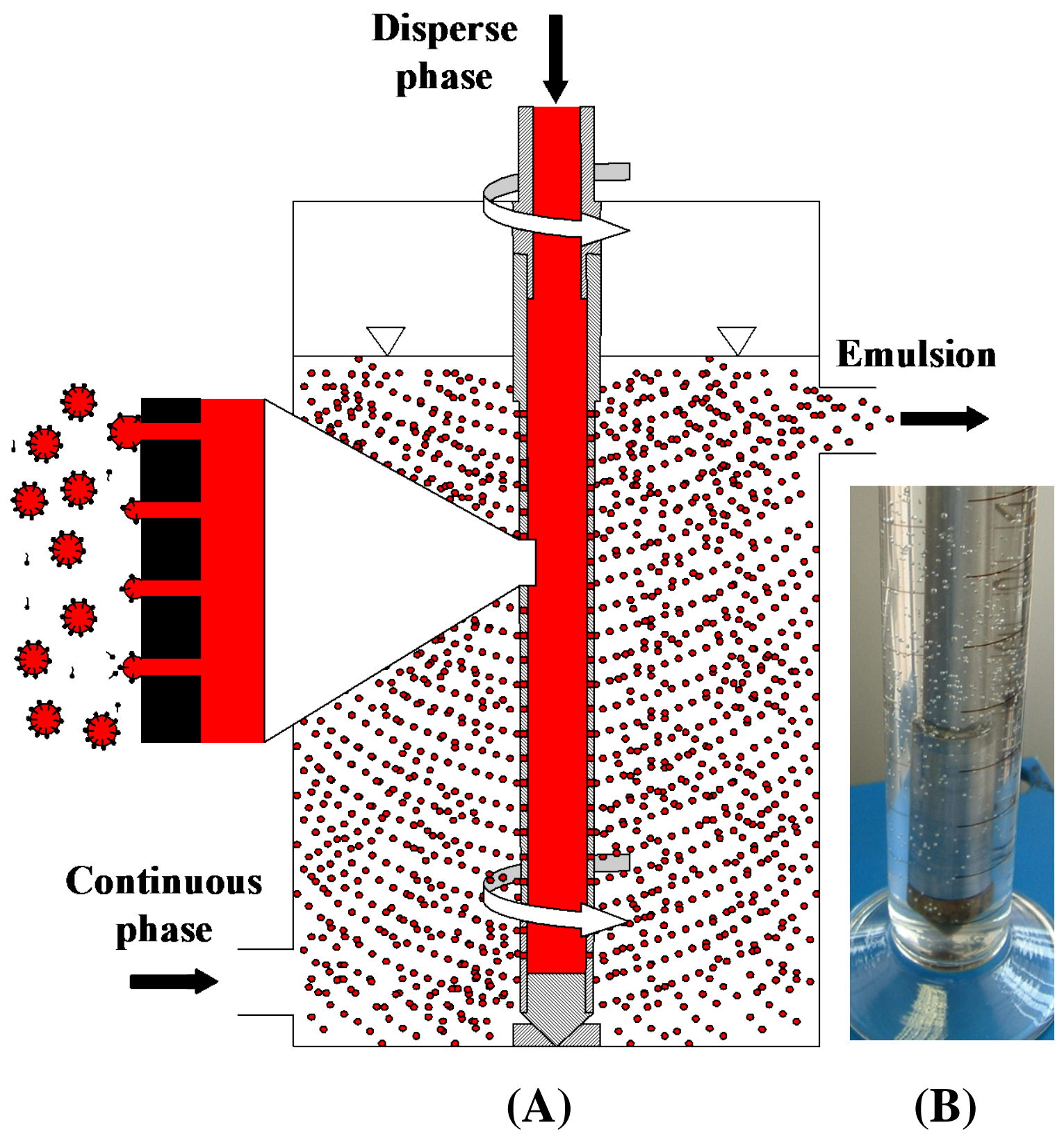

Fig. 1: (A) Schematic view of continuous rotating membrane emulsification system. (B) Batch rotating membrane system used in this work. 


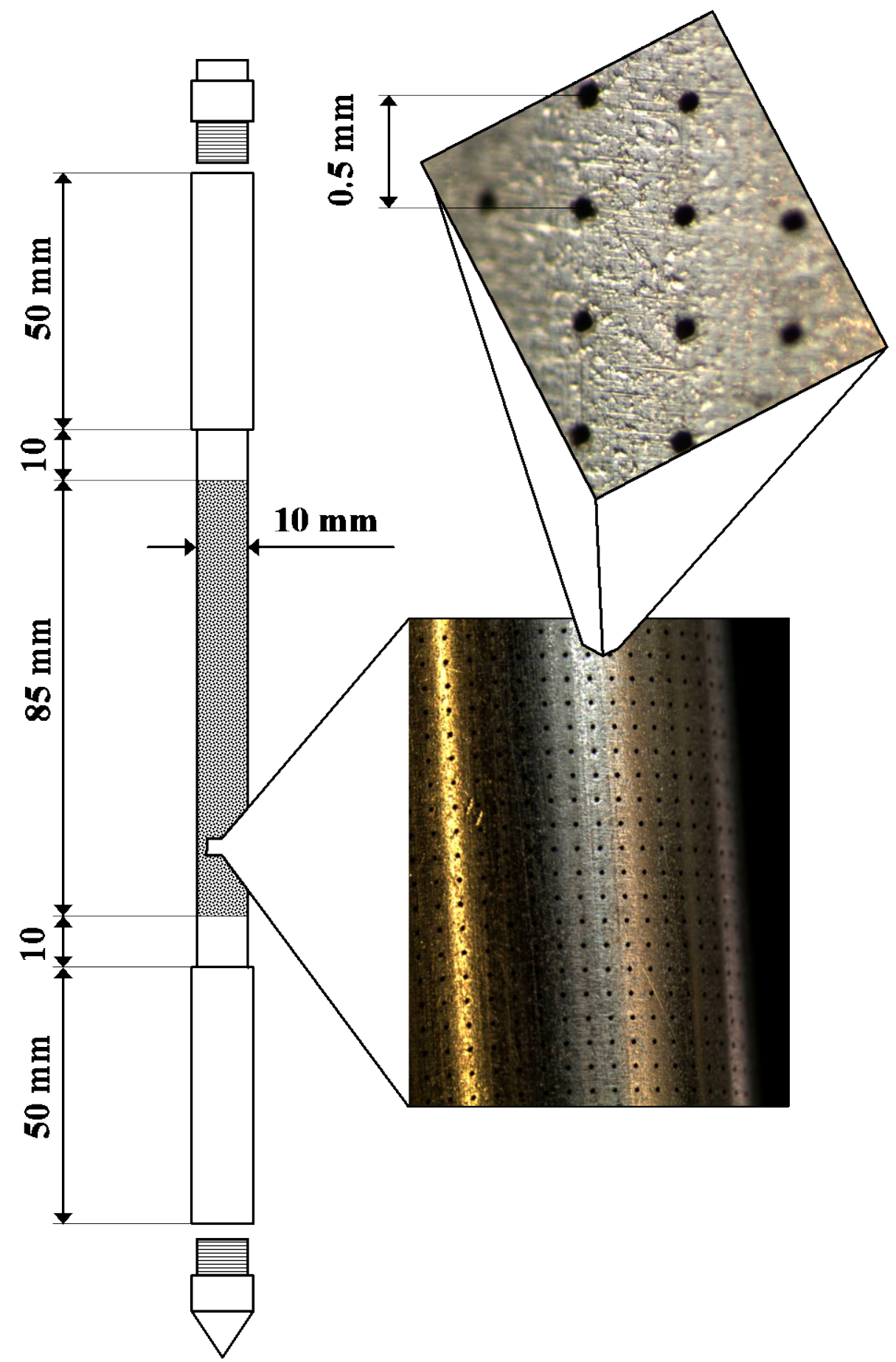

Fig. 2: Dimensions and pore arrangement of stainless steel membrane used in this work. 


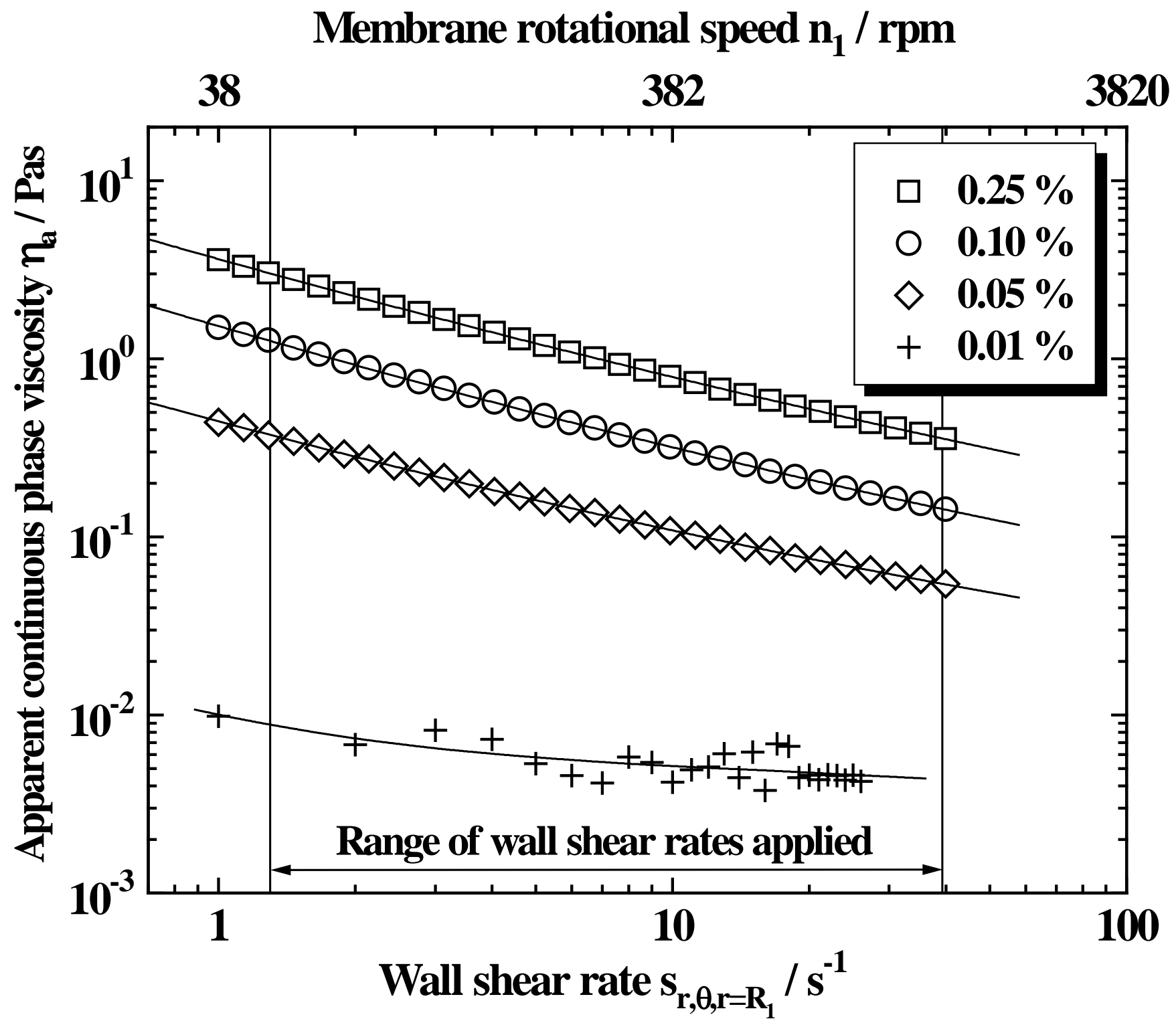

Fig. 3: Flow curves of the continuous phase at four different stabilizer contents. The range of shear rates applied in the experiments is shown by the arrows. 


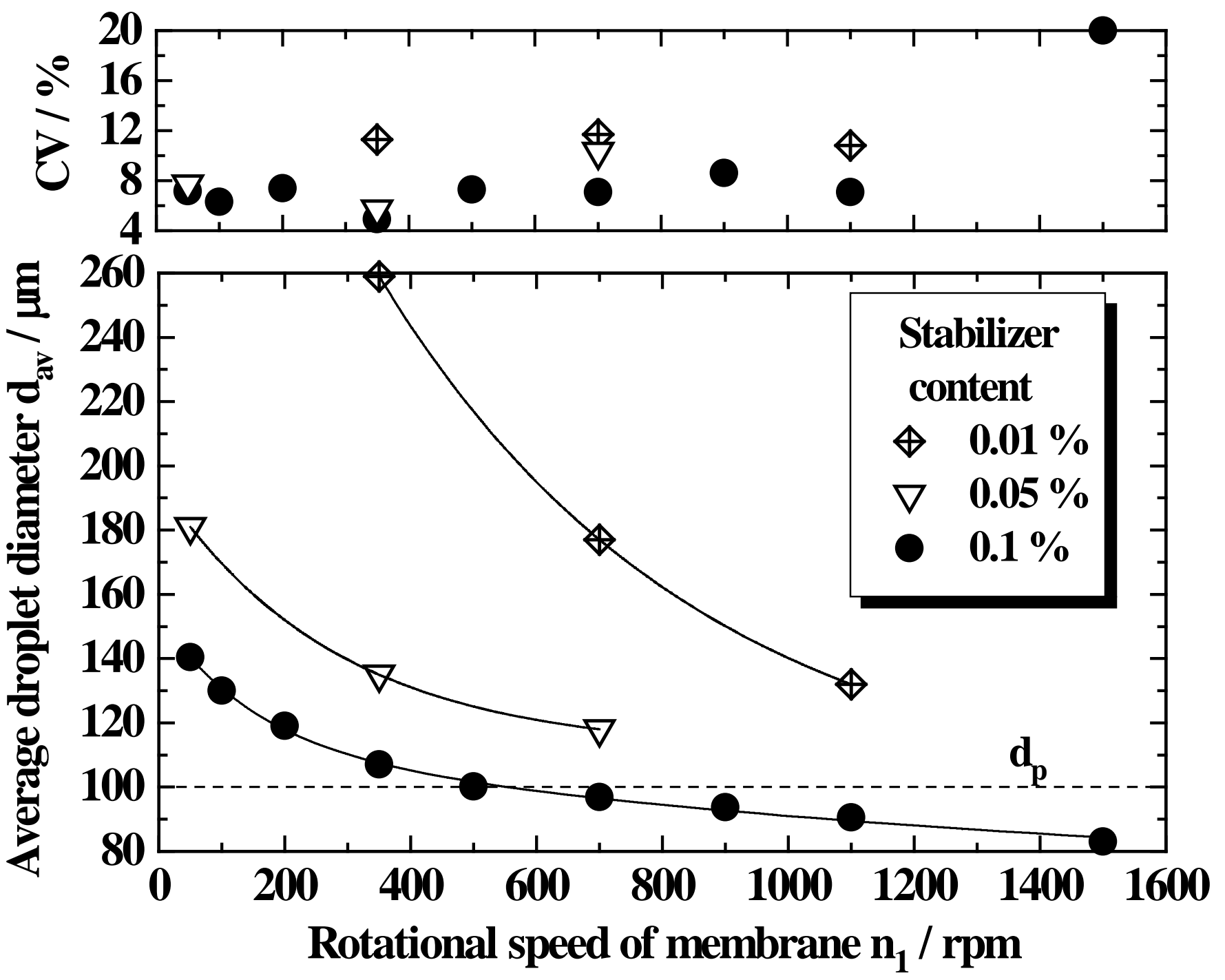

Fig. 4: Effect of membrane rotational speed on the average droplet diameter and the coefficient of variation of droplet diameters for three different stabilizer contents. 


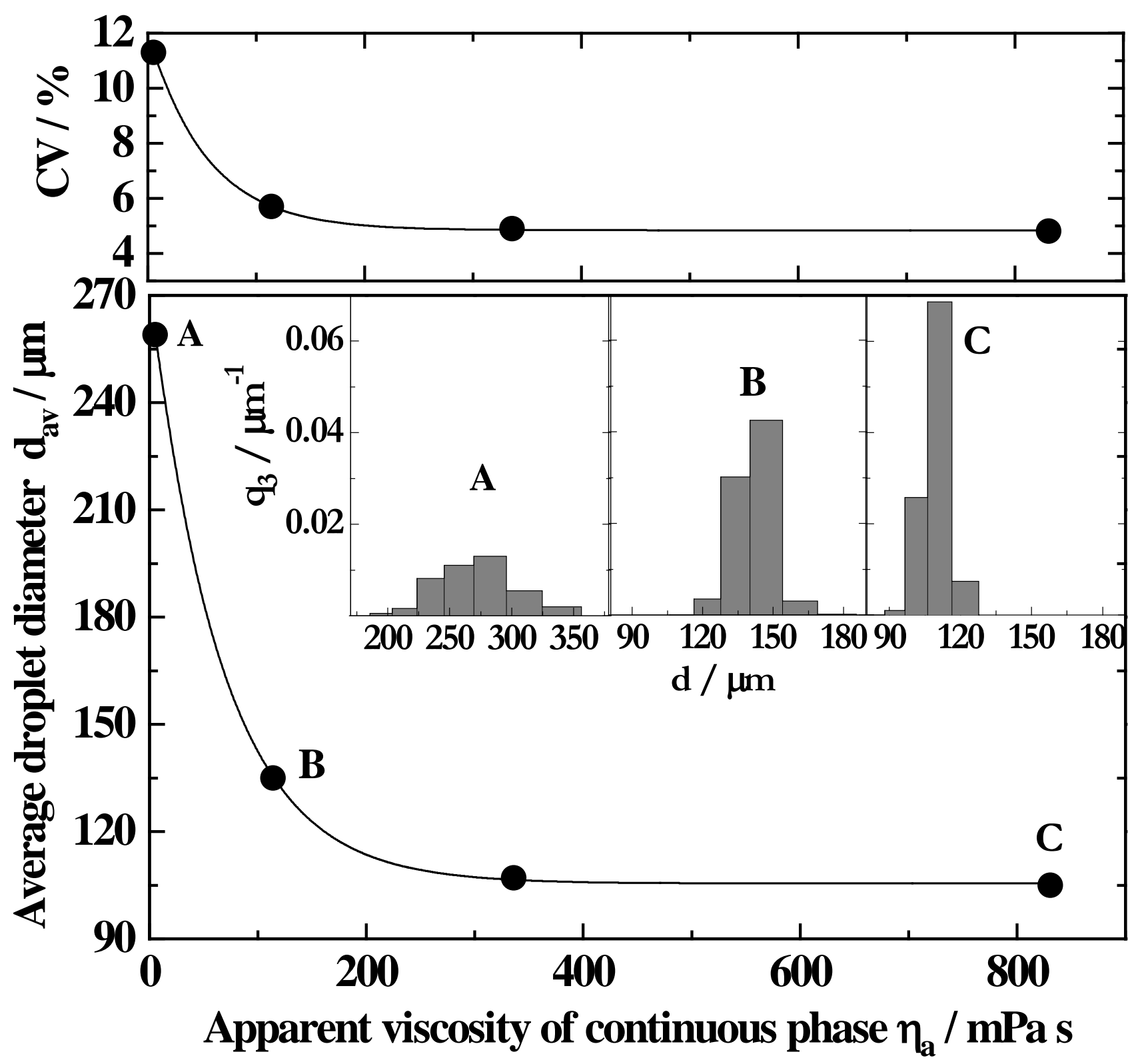

Fig. 5: Effect of apparent continuous phase viscosity on the average droplet diameter, and the $\mathrm{CV}$ at a fixed rotational speed of $350 \mathrm{rpm}$. The particle size distributions corresponding to the data points $\mathrm{A}, \mathrm{B}$, and $\mathrm{C}$ are shown as insets. 


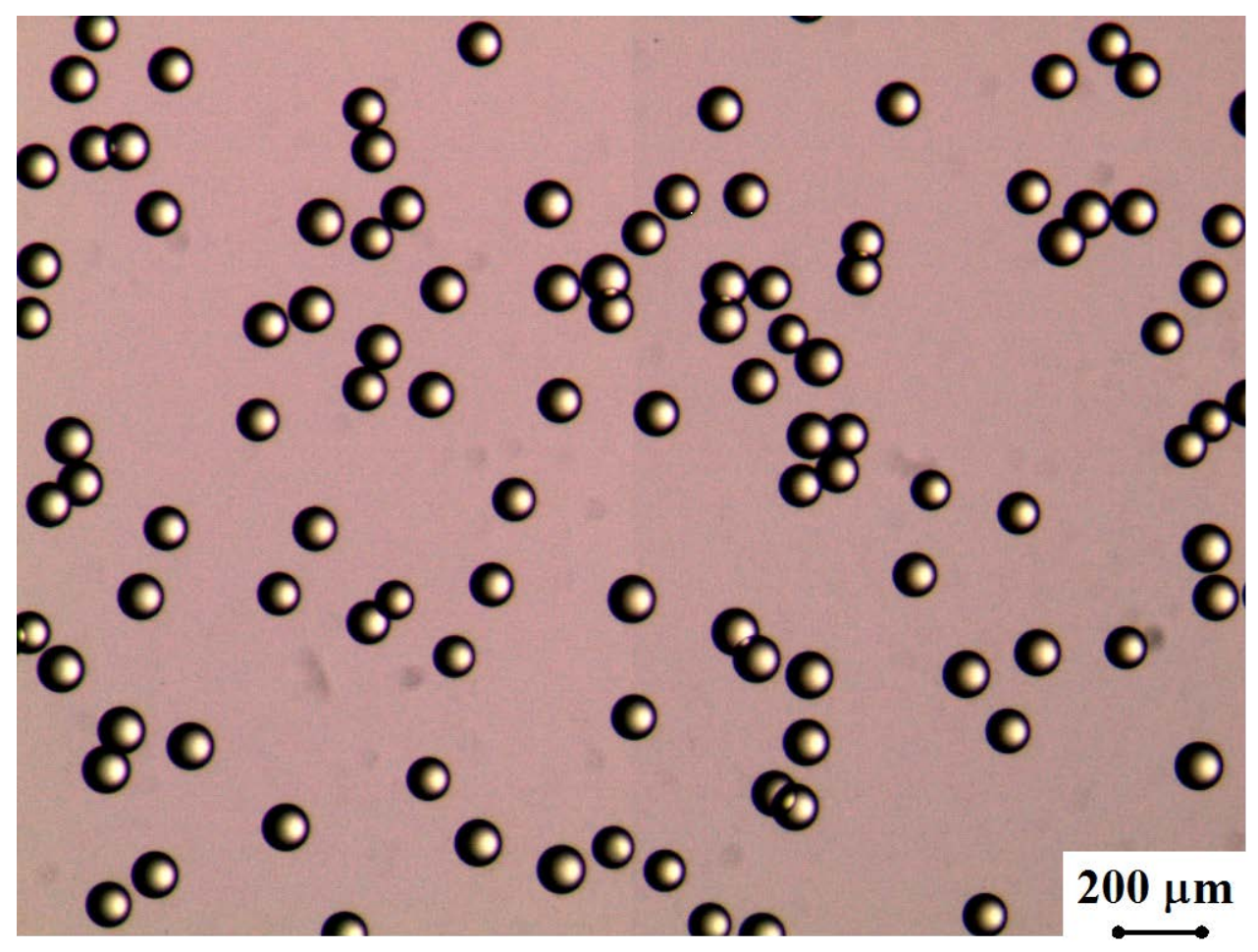

(A)

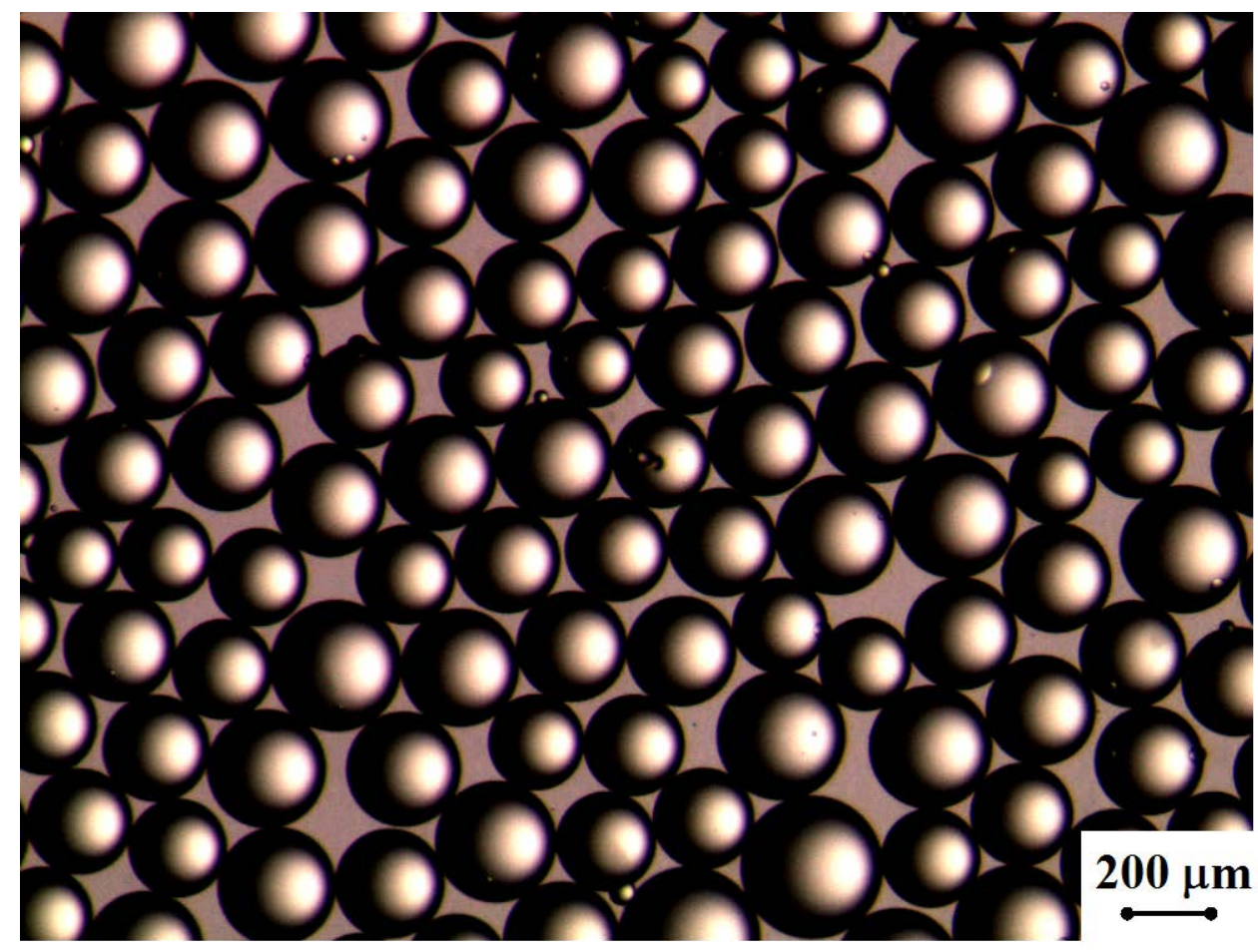

(B)

Fig. 6: Micrographs of the emulsion droplets produced at a fixed speed of rotation of 350 rpm using two different stabiliser contents: (A) 0.1 wt. \% Carbomer; (B) 0.01 wt. \% Carbomer. 


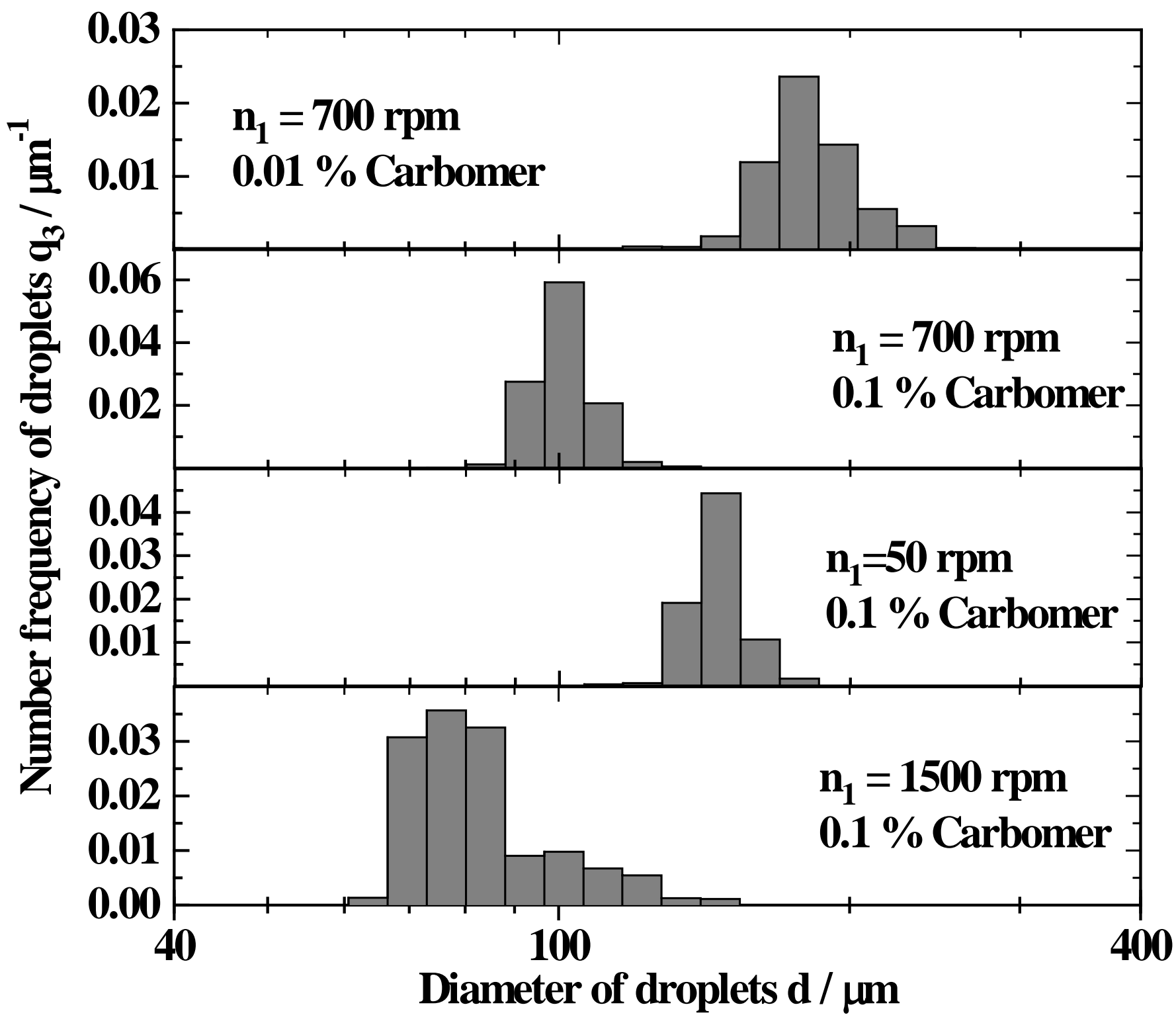

Fig. 7: Particle size distrubution data obtained under different operating conditions. 


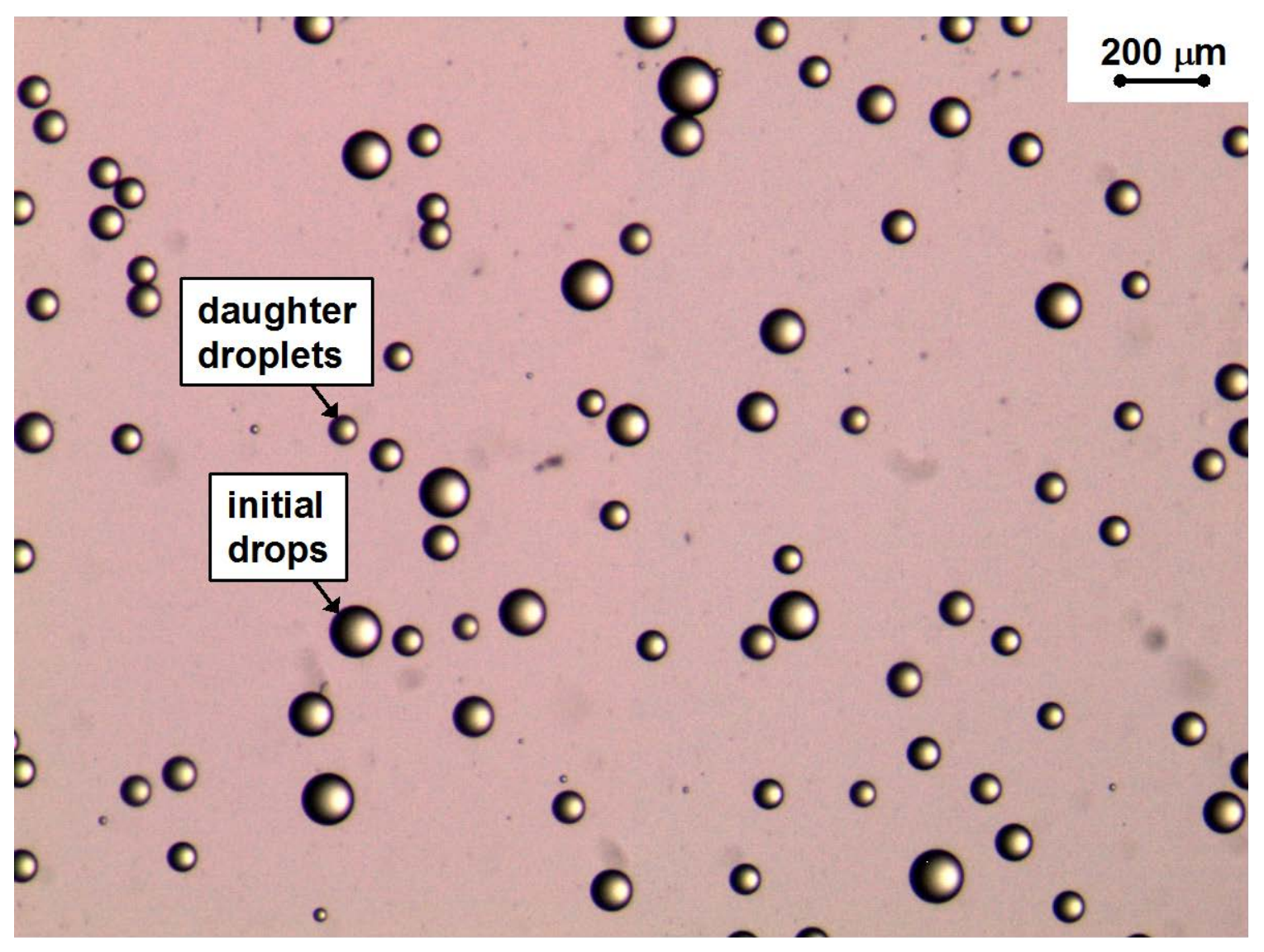

Fig. 8: Micrograph of the emulsion droplets produced at $1500 \mathrm{rpm}$ and a Carbomer content of 0.1 wt. \% $\left(d_{a v}=83 \mu \mathrm{m}, \mathrm{CV}=20 \%\right)$. 


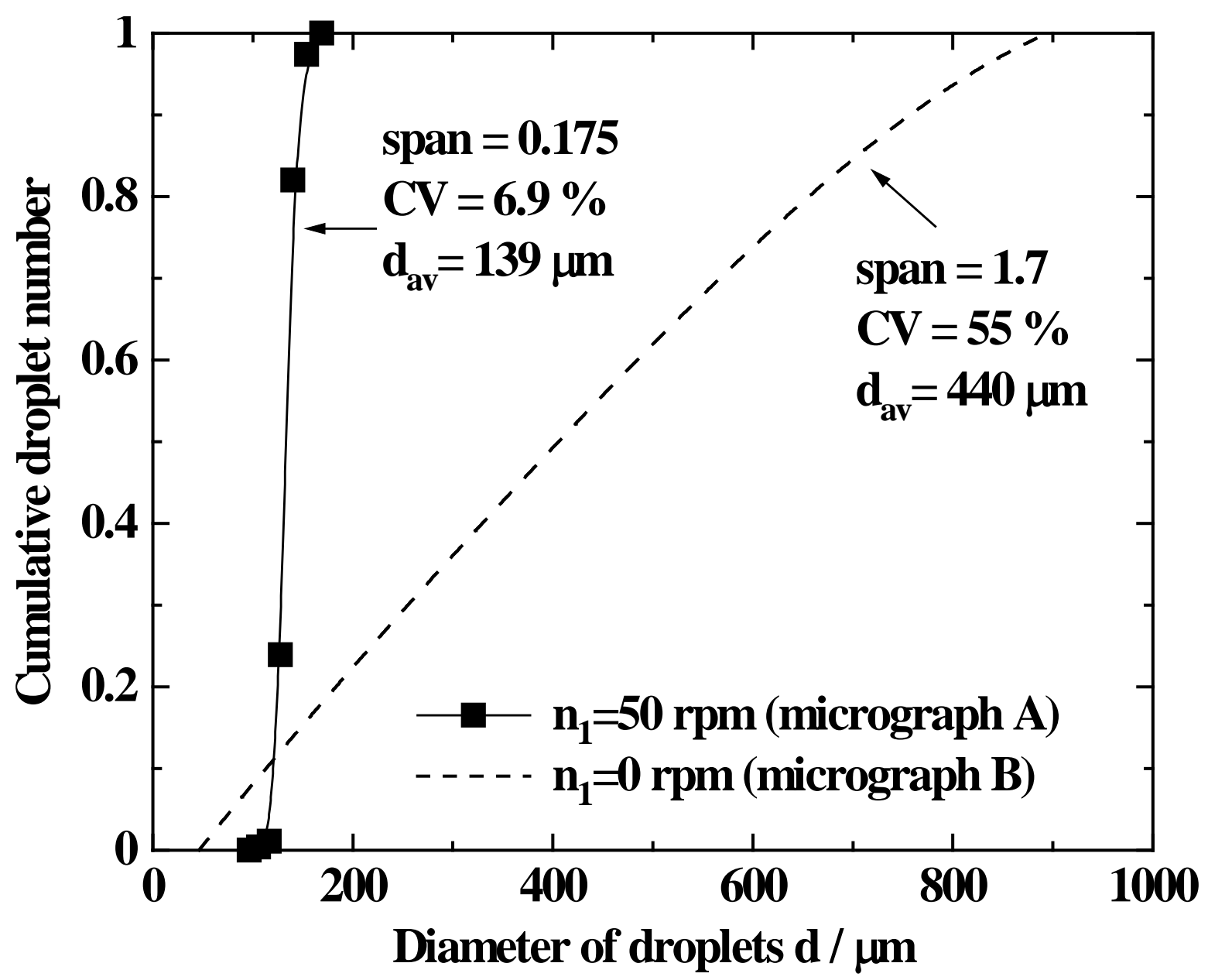

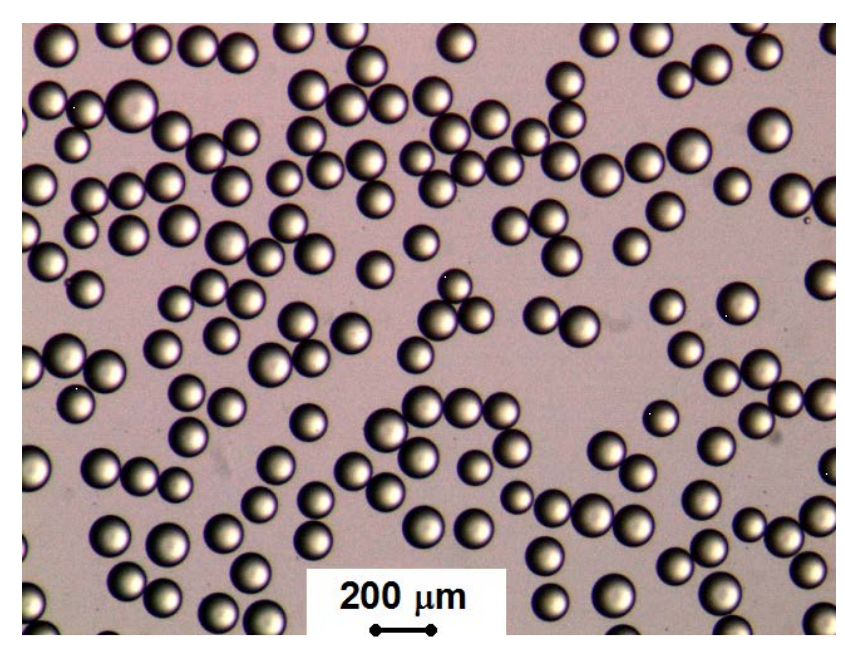

(A)

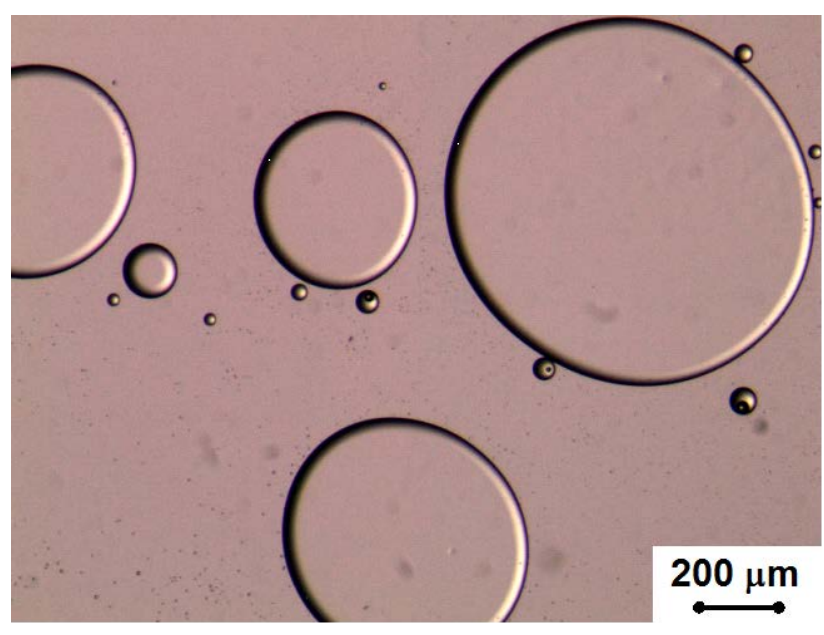

(B)

Fig. 9: Droplet size distributions for emulsions produced under stagnant conditions (0 rpm) and $50 \mathrm{rpm}$. (A) Micrograph of the emulsion droplets produced at $50 \mathrm{rpm}$. (B) Micrograph of the droplets produced under stagnant conditions. The Carbomer content was fixed at $0.1 \mathrm{wt}$. \%. 